\title{
REVIEW
}

\section{Rituximab-induced lung disease: a systematic literature review}

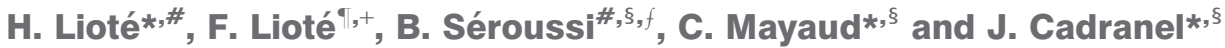

ABSTRACT: The anti-CD20 antibody rituximab has been reported to induce a heterogeneous spectrum of lung disorders. The aim of the present study was to critically review data on the clinical presentations, causality assessments and management strategies of lung diseases possibly related to rituximab.

A systematic literature review was performed on English-language reports in PubMed until September 2008.

Cases of lung diseases ascribed to rituximab $(n=45)$ were identified, with three time-to-onset patterns. The most common presentation was acute/subacute hypoxaemic organising pneumonia $(n=37)$, starting 2 weeks after the last infusion (often around the fourth cycle) and resolving, in most cases, provided glucocorticoid therapy was given early. Acute respiratory distress syndrome occurred in five patients, within a few hours and usually after the first infusion. In the remaining three patients, macronodular organising pneumonia developed insidiously long after rituximab therapy and responded to steroids. Eight patients died. Based on time to onset, symptoms, and responses to discontinuation and rechallenge with rituximab and other drugs, 13 cases were highly compatible and 32 compatible with rituximab-induced lung disease.

Knowledge of these presentations of rituximab-induced lung disease should prove helpful for diagnosis and causality assessment purposes. Time-to-onset data, suggesting different pathogenic mechanisms, support closer clinical and perhaps radiological monitoring between infusions, particularly in patients with a history of reversible respiratory symptoms.

KEYWORDS: Adverse effects, B-cell lymphoma, interstitial pneumonitis, organising pneumonia, rheumatoid arthritis, rituximab

$\mathbf{R}$ ituximab is a chimeric human-mouse immunoglobulin G1- $\kappa$ monoclonal antibody with high affinity for CD20 surface antigens expressed by normal human pre-B- and B-lymphocytes but not by stem or plasma cells. Binding of the antibody to CD20 causes cell lysis via activation of the complement cascade and natural killer cells. Accelerated apoptosis and sensitivity to antineoplastic agents are also induced by the drug [1]. Rituximab may persist in the body for several months. Peripheral B-cell depletion lasts 6-9 months after treatment in most patients [2].

Rituximab is the major step forward in lymphoma treatment since the late 1990s. It was approved by the Food and Drug Administration in 1997 and by the European Agency for the Evaluation of Medicinal Products (EMEA) in
1998 for low-grade non-Hodgkin's lymphoma expressing CD20 and chronic lymphocytic leukaemia, and subsequently diffuse large B-cell non-Hodgkin's lymphoma [3]. In 2006, the EMEA approved rituximab for rheumatoid arthritis (RA) in adults [4]. Uses in idiopathic thrombocytopenic purpura (ITP) [5], autoimmune haemolytic anaemia, Sjögren's syndrome, systemic lupus and systemic vasculitis are undergoing evaluation. Patients with lymphoma are given one to six infusions of $375 \mathrm{mg} \cdot \mathrm{m}^{-2}$ at intervals depending on the treatment protocol. In RA, $1,000 \mathrm{mg}$ is given twice, with a 2 -week interval, followed by retreatment 6 months later if needed.

From safety data on 960,000 patients treated worldwide up to 2007 [2, 6-8], rituximab was well tolerated. However, side-effects were recorded in phase III controlled trials and post-marketing

\section{AFFILIATIONS}

*Service de Pneumologie et

Réanimation, Centre de compétence maladies pulmonaires rares, Hôpital Tenon, Assistance Publique-Hôpitaux de Paris (AP-HP)

\#Dept de Santé Publique, Hôpital Tenon, AP-HP

"Fédération de Rhumatologie, Pôle appareil locomoteur, Centre ViggoPetersen, Hôpital Lariboisière, APHP,

+Paris Diderot University,

${ }^{\S}$ Pierre and Marie Curie University, Paris, and

${ }^{f}$ Laboratoire d'informatique médicale et de bioinformatique, Unité de Formation et de Recherche SantéMédecine-Biologie humaine, Paris 13 University, Bobigny, France.

CORRESPONDENCE

H. Lioté

Service de Pneumologie et

Réanimation,

Centre de compétence maladies pulmonaires rares Hôpital -Tenon (AP-HP) 4 rue de la Chine 75970 Paris Cedex 20 France

E-mail: huguette.liote@tnn.aphp.fr

Received:

May 182009

Accepted after revision: July 072009 First published online: July 162009 
surveillance programmes, with less severity in RA than in lymphoma [2, 9]. Infusion-related reactions (IRRs) occurred in $9-15 \%$ of patients. IRRs consist of influenza-like symptoms, with respiratory manifestations in $30 \%$ of cases. Patients may experience anaphylactic shock or, more rarely, acute respiratory distress syndrome (ARDS), fatal in $0.04-0.07 \%$. These serious side-effects have led the pharmaceutical companies that market rituximab to recommend a number of precautions (table 1) [10]. Although the rate of delayed neutropenia was slightly increased, the immediate risk of infection, namely pulmonary infection, was not increased, and data were incomplete regarding the risk of delayed infection [11]. Severe delayed lung injury was noted with a rate of occurrence of $0.03 \%$ in the review of KIMBY [2] and $0.01 \%$ in the Spanish pharmacovigilance database [9]. Of all sideeffects of rituximab, lung disease may have by far the highest reporting odds ratio (ROR; 68.1; 95\% confidence interval 23.8194.9) [9].

The present study was performed for several reasons: lung disease was not documented in the clinical trials, the drug is being used increasingly as mentioned before [4], and case reports of possible rituximab-induced lung disease are accumulating at a fast pace. The primary objective of this systematic literature review was to obtain a comprehensive picture of the pulmonary side-effects of rituximab and to provide a diagnostic standard (for drug causality assessment) $[12,13]$. Time to onset was also evaluated for features that

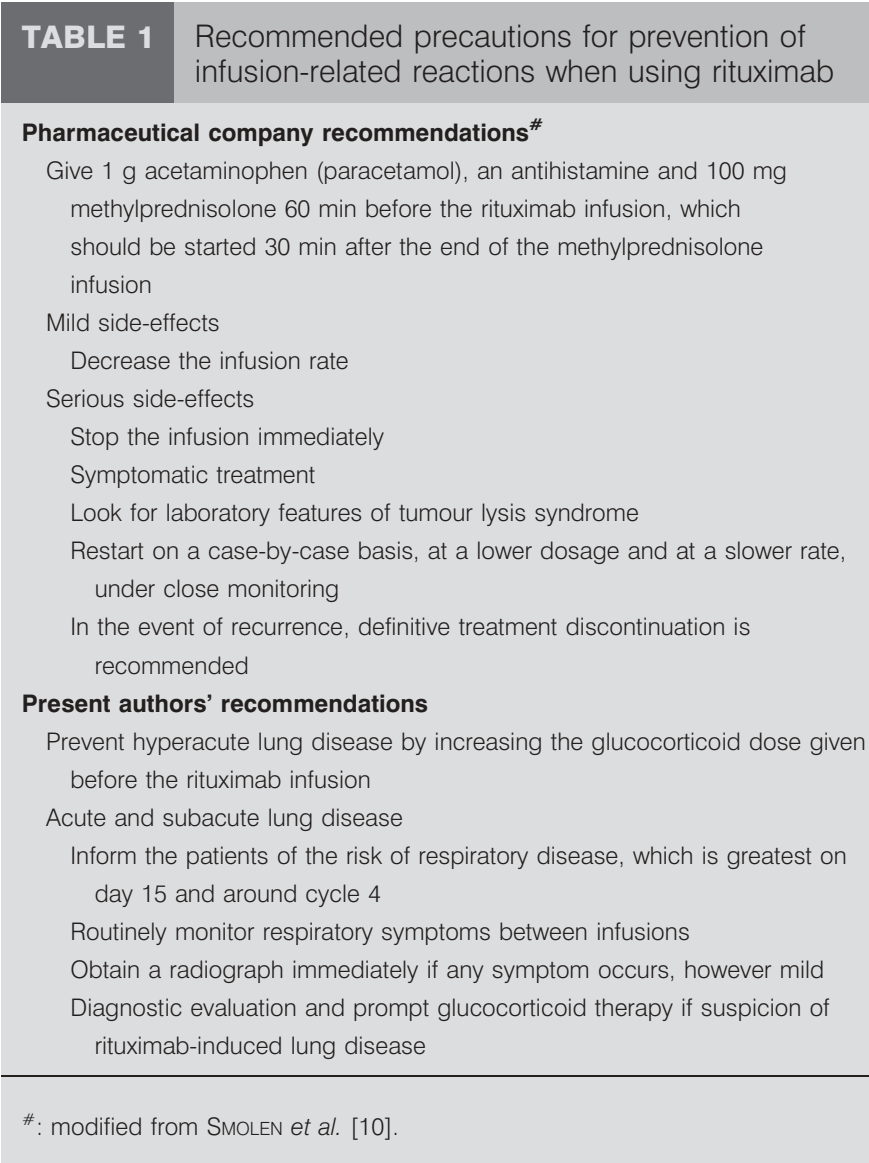

might help in the development of protective measures for clinical practice.

\section{METHODS}

\section{Data sources and searches}

According to Cochrane Reviews methodology, a systematic literature review was conducted for case reports in English or French indexed in PubMed between 1997 (the year of licensure of rituximab) and September 2008.

\section{Study selection}

The following Medical Subject Heading (MeSH) terms were used: "rituximab" AND "adverse effects" AND "interstitial pneumonitis" OR "idiopathic interstitial pneumonitis" OR "organizing pneumonia". Subsequently, a search was conducted using "rituximab" combined with "respiratory side effect", "drug reaction" or "pulmonary toxicity". The references of the articles retrieved by the PubMed search were searched manually. Abstracts from meetings with no corresponding full-length publication were not considered. For each reported case, the country and city were recorded in order to eliminate redundancies.

\section{Data extraction and quality assessment}

When available, seven categories of data were extracted from each case report: 1) patient characteristics (age, sex, geographic origin and reason for rituximab therapy); 2) treatment modalities (dosage, number of cycles and cumulative dose); 3) time to onset (time between the last rituximab infusions and respiratory symptoms) and whether symptoms had occurred following previous cycles; 4) tempo of onset (hyperacute: development of pneumonitis within hours after the first symptom; acute or subacute: development over a few days; and chronic: development over several weeks or months); 5) respiratory and extra-respiratory manifestations (clinical and radiological features, computed tomographic findings, cytological studies of bronchoalveolar lavage fluid (BALF), and histological findings from transbronchial and/or open lung biopsy specimens); 6) therapeutic management (discontinuation of rituximab alone or of all chemotherapy agents, and steroid therapy) and course; and 7) whether subsequent treatment involved the use of rituximab (alone or with other chemotherapy agents) or other chemotherapy agents without rituximab, and whether re-exposure to rituximab of patients with respiratory symptoms at one or more earlier cycles was intentional or unintentional (e.g. in patients with self-limited symptoms identified retrospectively).

Study quality was assessed independently by two reviewers, one with expertise in drug-induced lung diseases and one with expertise in research methods. The following key design features were evaluated: presence of valuable data, especially for time to onset; exclusion of other causes; and re-introduction conditions. Disagreements were resolved by independent adjudication.

\section{Data synthesis and analysis}

Numerical data are expressed as mean, range and percentage. A Chi-squared test for independence was used to compare the two distributions, namely, time since the last infusion and tempo of onset since the first symptom. 


\section{RESULTS}

\section{Number of articles retrieved and numbers of included and excluded cases}

A total of 52 cases were identified (fig. 1) [3, 14-41], described in anecdotal case reports and in nine case series reporting two cases [16, 21, 29, 34, 35], three cases [19, 33], four cases [38] or nine cases [39]. A few adequately documented cases occurred during clinical trials. Seven out of these 52 cases were excluded due to insufficient detail about cases that occurred in clinical trials $(n=2)$ [15], the time to onset being too long to be compatible with causality of rituximab $(n=2$, one case each of fluctuant macronodular organised pneumonia 9 months after the last infusion in a patient with Castleman disease [16] and constrictive bronchiolitis 10 months after the last infusion [14]) and manifestations unrelated to rituximab-induced lung disease (one case each of heart failure ascribed to direct myocardial toxicity of rituximab [3], fludarabine-induced lung disease confirmed by a positive rechallenge test result [3] and fatal haemoptysis complicating necrotising lymphomatoid granulomatosis of the lung [41]). This left 45 cases of possible rituximab-induced lung disease for the present study.

\section{Characteristics of the patients}

The mean (range) age of the patients was 65 (43-80) yrs, and the male:female ratio was 2:1. Of the 45 patients, 17 (38\%) were in Asia, 12 were in the Americas (and their ethnic origin was not reported) and 16 were in Europe. The rate of occurrence was $8.4 \%$ (nine out of 107) in the Korean case series [39] and $11 \%$ (four out of 36) in the Dutch case series [38]. The reason for rituximab therapy was diffuse large B-cell lymphoma in 30 patients, indolent lymphoma in 10 (mantle cell lymphoma $(n=2)$ [20, 21, 39], marginal zone lymphoma or mucosaassociated lymphoid tissue (MALT) $(n=3)$ [22, 32, 33], follicular lymphoma $(n=4)[24,32,39]$ and Waldenström's macroglobulinaemia $(n=1)$ [38]), chronic lymphocytic leukaemia in two $[3,37]$, ITP in two $[18,26]$ and RA in one [16].

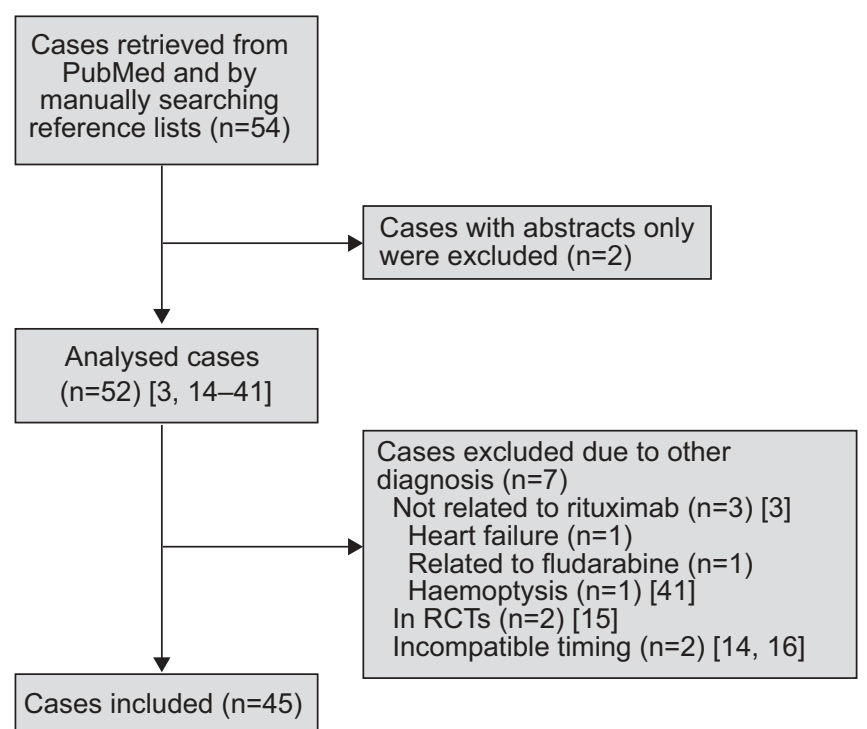

FIGURE 1. Flow chart showing the total number of cases retrieved by the literature search and the numbers of excluded and included cases. RCT: randomised controlled trial

\section{Modalities of rituximab administration}

Overall, rituximab was given at a mean dosage of $375 \mathrm{mg} \cdot \mathrm{m}^{-2}$ per intravenous cycle on 1 or 2 days consecutively. The interval between cycles was 8,15 or 21 days. Rituximab alone was used in seven patients [20, 21, 24, 26, 33, 37, 40], and with stable-dosage methotrexate for maintenance therapy of RA in one [16]. The other 37 patients received rituximab in combination with multiple chemotherapy regimens (COP, $\mathrm{CHOP}$, CEOP, CVP, ACVBP, VNCOP, fludarabine, cladribine and growth factors (where $\mathrm{C}$ is cyclophosphamide, $\mathrm{O}$ vinblastine, $\mathrm{P}$ prednisone, $\mathrm{H}$ doxorubicin, $\mathrm{E}$ epirubicin, $\mathrm{V}$ etoposide, $\mathrm{A}$ Adriamycin, B bleomycin and $\mathrm{N}$ mitoxantrone)).

\section{Time-to-onset data}

The mean time from the first rituximab infusion to onset of the respiratory manifestations $(n=21)$ was 3 months (12 weeks), with a peak at the fourth cycle (fig. 2a) and a mean cumulative dosage of $1,600 \mathrm{mg} \cdot \mathrm{m}^{-2}$. The histogram of time to onset from the last rituximab infusion clearly shows three peaks (fig. 2b). The first peak, with five patients [17-19], occurred a few hours after the infusion (day 1), i.e. reflected early-onset forms. The second peak, with 29 patients, occurred exactly on day 15, and eight additional cases occurred a few days before (days 8-15) or after (days 15-21) this second peak. Thus 37 patients experienced delayed-onset forms [3, 20-39]. Finally, the third peak reflected late-onset forms, occurring 1-3 months after the last infusion in three patients [16, 33, 40].

\section{Tempo of onset}

The tempo of onset (table 2) was usually acute or subacute (36 patients) [3, 20, 21, 23-39]. In six patients, the onset was hyperacute [17-19], and, in three patients, it was chronic [16, $33,40]$. The distributions of tempo of onset and time to onset from the last rituximab infusion showed a nearly perfect match (table 2$)$ and were significantly linked $\left(p<1 \times 10^{-16}\right)$ : the five early-onset cases were hyperacute; 36 out of the 37 delayedonset cases were acute or subacute; and the three late-onset cases were chronic.

\section{Symptoms and course}

Early-onset hyperacute forms

All five patients in this group had ARDS with arterial oxygen tensions $\left(\mathrm{Pa}_{\mathrm{a}} \mathrm{O}_{2}\right)$ of $<50 \mathrm{mmHg}$. A single patient underwent lung biopsy, which showed diffuse alveolar damage and intraalveolar haemorrhage [19]. All five patients required mechanical ventilation and received a bolus of steroids. Two patients died.

Of the five patients, four were receiving combination chemotherapy regimens and four experienced ARDS following the first rituximab cycle. The recommended pre-medication was given to four patients; for the remaining patient, this information was not available. Rechallenge was performed in two patients and gave negative results in both, despite the absence of additional precautions [19].

\section{Delayed-onset acute forms}

Of the 37 patients in this group, 34 had non-Hodgkin's lymphoma, two had chronic lymphocytic leukaemia and one had ITP. Rituximab was used alone in four patients, and with combination chemotherapy in 33. Onset occurred after the third, fourth or fifth cycle in 18 of the 32 patients for whom this 

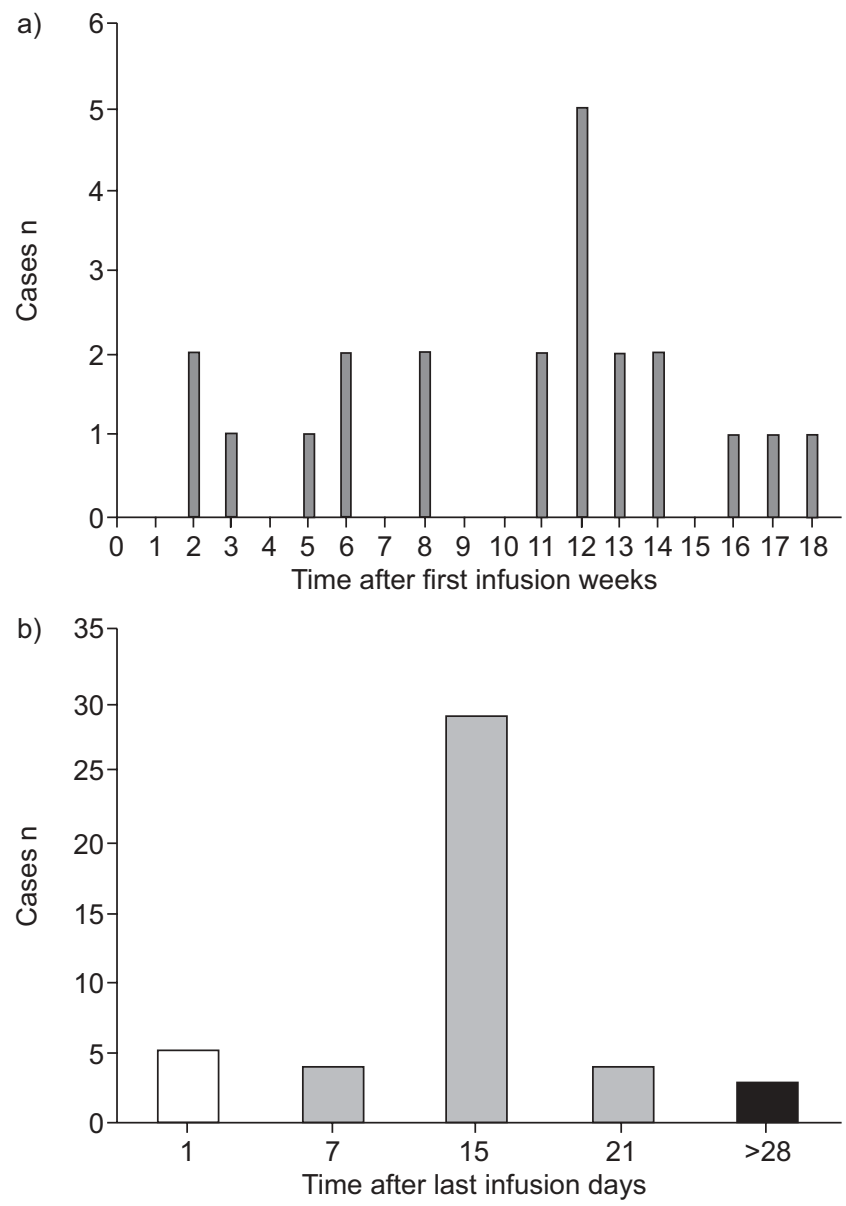

FIGURE 2. Time to onset of the respiratory manifestations from a) the first rituximab infusion and b) the last rituximab infusion. $\square$ : hyperacute early-onset forms; : acute and subacute delayed-onset forms;

chronic late-onset forms.

information was available, and on day 15 after the infusion in 29 out of the 37 patients. Earlier infusions had been followed, in nine patients, by respiratory symptoms consisting of coughing, dyspnoea or reversible bronchospasm [3, 20, 21, $25,26,31,33,38]$. These symptoms were not consistently present following the first cycle. They occurred repeatedly in eight patients (twice in three, three times in two, four times in two, and five times in one).

The clinical and radiological features are shown in table 3. The main manifestations were dyspnoea and fever. Hypoxaemia with $\mathrm{Pa}, \mathrm{O}_{2}$ of $<60 \mathrm{mmHg}$ was the rule. Computed tomography of the chest showed focal alveolar densities in $54 \%$ of patients, usually at multiple sites and in combination with ground-glass attenuation $(32 \%)$. Positron emission tomography was performed in seven patients and consistently showed an early increase in tracer uptake [31, 33, 38]. Findings from microbiological studies were negative $(n=40)$, including those on BALF. Failure of empirical antibiotic treatment was mentioned for 20 patients.

BALF cytology results were available for nine patients [22, 28$30,34,37,38]$. A consistent finding was lymphocytosis (13$90 \%$, with a predominance of CD4+ T-cells. Histological data were obtained (table 3 ) by surgical lung biopsy in six patients

\begin{tabular}{|c|c|c|c|c|c|}
\hline TABLE 2 & \multicolumn{5}{|c|}{$\begin{array}{l}\text { Distribution of cases by time to onset from the } \\
\text { last rituximab infusion and by tempo of } \\
\text { respiratory symptom development after the first } \\
\text { symptom }\end{array}$} \\
\hline \multirow{2}{*}{\multicolumn{2}{|c|}{ Tempo of onset }} & \multicolumn{3}{|c|}{ Time to onset } & \multirow[t]{2}{*}{ Total } \\
\hline & & Early & Delayed" & Late $^{+}$ & \\
\hline \multicolumn{2}{|l|}{ Hyperacute $^{\S}$} & 5 & 1 & & 6 \\
\hline \multicolumn{2}{|c|}{ Acute/subacute ${ }^{f}$} & & 36 & & 36 \\
\hline \multicolumn{2}{|l|}{ Chronic $^{\# \#}$} & & & 3 & 3 \\
\hline \multicolumn{2}{|l|}{ Total } & 5 & 37 & 3 & 45 \\
\hline
\end{tabular}

$[3,23-25,32,33]$ and by transbronchial lung biopsy in five [27, 31, 35-37]. According to the American Thoracic Society/ European Respiratory Society classification [42], the predominant histological pattern was organising pneumonia (eight out of $11 ; 72 \%)[23-25,27,31-33,37]$, isolated $(n=5)$ or associated with nonspecific interstitial pneumonia or usual interstitial pneumonia. None of the patients exhibited nonspecific interstitial pneumonia or usual interstitial pneumonia as the only histological pattern.

Of the 37 patients in this group, 10 required mechanical ventilation [20, 23-25, 28, 29, 31-33, 35]. Six patients died, including

\begin{tabular}{|c|c|c|}
\hline TABLE 3 & \multicolumn{2}{|c|}{$\begin{array}{l}\text { Clinical, computed tomography }(\mathrm{CT}) \text { and } \\
\text { histological findings in patients with acute or } \\
\text { subacute rituximab-induced lung disease }\end{array}$} \\
\hline \multicolumn{3}{|c|}{ Clinical features $\#$} \\
\hline Cough & & $16(43)$ \\
\hline Dyspnoea & & $30(85)$ \\
\hline Fever & & $23(62)$ \\
\hline Crepitant ra & & $13(35)$ \\
\hline Hypoxia & & $15(37)$ \\
\hline $\mathrm{Pa}, \mathrm{O}_{2}<60 \mathrm{n}$ & $\mathrm{mHg}$ & $8(53)^{\S}$ \\
\hline Chest pain & & 1 \\
\hline Rash and $\mathrm{h}$ & pereosinophilia $\mathrm{n}$ & 2 \\
\hline \multicolumn{3}{|c|}{ Predominant CT pattern ${ }^{\#}$} \\
\hline Focal alveol & a pattern $\geqslant 1^{\bullet}$ & $19(54)$ \\
\hline Ground-glas & s opacities & $12(34)$ \\
\hline Diffuse alve & lar pattern & $3(8.5)$ \\
\hline Macronodul & $\mathrm{s} n$ & 1 \\
\hline \multicolumn{3}{|c|}{ Histological pattern ${ }^{+}$} \\
\hline Organising & neumonia & $8(5)$ \\
\hline Nonspecific & nterstitial pneumonia & $4(0)$ \\
\hline Usual inters & tial pneumonia & $2(0)$ \\
\hline Diffuse alve & lar damage & $2(0)$ \\
\hline Intra-alveola & haemorrhage & $2(0)$ \\
\hline
\end{tabular}

Unless otherwise indicated, data are presented as $n$ (\%), except for histological pattern, which is presented as $n$ (number with isolated pattern). $\mathrm{Pa}, \mathrm{O}_{2}$ : arterial oxygen tension. ${ }^{\#}: \mathrm{n}=37$ [3, 20-39]; ${ }^{\uparrow}: \geqslant 1$ focal alveolar infiltrates; ${ }^{+}$: evaluated by lung biopsy $(n=11)[3,23-25,27,31-33,35-37]$; ${ }^{\S}$ : of $n=15$ with hypoxia. 
two with a history of respiratory symptoms following previous cycles $[25,31]$. Of the six patients who died, only one was receiving rituximab alone, for follicular lymphoma [24]. The 31 survivors made a full recovery, with clinical resolution within a few days and imaging resolution within a few weeks. In 27 patients, simultaneous steroid therapy was given.

Rituximab was reintroduced in 15 patients with previous respiratory manifestations, either intentionally or unintentionally (table 4). The rechallenge gave positive results in four patients with rituximab alone [20, 31, 26, 38], and in eight patients with rituximab and combination chemotherapy $[3,25$, $31,34,38,39]$. The rechallenge gave negative results in three patients who concomitantly received high-dose steroids $\left(1 \mathrm{mg} \cdot \mathrm{kg}\right.$ body weight $\left.{ }^{-1}\right)$ independent of the recommended prophylactic methylprednisolone therapy. Finally, nine patients experienced no further respiratory symptoms when their chemotherapy was restarted without rituximab [22, 25, 27, 29, $38,39]$.

\section{Late-onset chronic forms}

The mean time to onset in these three patients was 8 weeks from the last rituximab infusion. The symptoms started after the second, third and fifth cycles. None of these patients were receiving anticancer chemotherapy. The diagnoses were RA [16], gastric MALT lymphoma [33] and Waldenström's macroglobulinaemia [40]. Clinically silent pulmonary macronodules and BALF lymphocytosis were the only manifestations. Lung biopsy was performed in all three patients and consistently showed organising pneumonia. Steroid therapy ensured a full recovery in all three patients. None of these patients were rechallenged with rituximab.

\section{DISCUSSION}

The present systematic review confirms that rituximab can cause pulmonary toxicity. Three clinical presentations were identified based on time to onset and symptoms. The most common presentation by far was acute or subacute organising pneumonia, occurring $\sim 2$ weeks after the last infusion and rapidly causing hypoxaemia but responding favourably to early steroid therapy. More rarely, the pulmonary toxicity of

\begin{tabular}{|c|c|c|c|}
\hline TABLE 4 & \multicolumn{3}{|c|}{$\begin{array}{l}\text { Results of rechallenge with rituximab (RTX) and/ } \\
\text { or other drugs in patients with any clinical pattern } \\
\text { of lung disease }\end{array}$} \\
\hline \multicolumn{2}{|c|}{ Drug causation } & Patients n & [Refs] \\
\hline \multicolumn{4}{|c|}{ Highly compatible } \\
\hline \multicolumn{2}{|c|}{ Positive to RTX alone } & 4 & {$[20,21,26,38]$} \\
\hline \multicolumn{2}{|c|}{ Negative to chemotherapy without RTX } & 9 & {$[22,25,27,29,38,39]$} \\
\hline \multicolumn{2}{|l|}{ Total } & 13 & \\
\hline \multicolumn{4}{|l|}{ Compatible } \\
\hline \multicolumn{2}{|c|}{ Positive to chemotherapy with RTX } & 8 & {$[3,25,31,33,38,39]$} \\
\hline \multicolumn{2}{|c|}{ No rechallenge } & 19 & \\
\hline \multicolumn{2}{|c|}{ Negative to RTX\# } & 5 & {$[19,30,39]$} \\
\hline \multicolumn{2}{|l|}{ Total } & 32 & \\
\hline
\end{tabular}

rituximab manifested as early and potentially fatal ARDS or as chronic macronodular organising pneumonia.

\section{Causality}

Although there is no consensus regarding the best method of assessing causality [43], the criteria generally used to evaluate drug-induced lung disease (table 5) [12, 13, 44] support a causal link with rituximab in all 45 patients. The time to onset, clinical and radiological features, and cytohistological findings were consistent with drug-induced lung disease. Other causes of pneumonia were considered and ruled out in most patients. The histological data and course excluded pulmonary lymphoma relapse, lymphoma-related organising pneumonia [45], rheumatoid lung disease and other respiratory diseases. Doubtful cases were excluded [14-16]. Respiratory tract infection was ruled out by negative microbiological studies, including tests for opportunistic pathogens in BALF, and by a negative response to antibiotics. Exacerbation of a cardiac or previous respiratory disease was excluded [3]. The full recovery achieved by survivors of the acute-subacute episodes following rituximab discontinuation should be interpreted with caution. Five patients received steroid therapy, which is known to improve lung disease due to other causes. Only seven patients were taking rituximab alone. In the other patients, it is unclear which drug or drug combination was responsible for the respiratory manifestations. Indeed, similar times to onset and features of pneumonitis have been reported with the associated drugs [46]. The results of rechallenge with the drug (table 4), usually considered a major causality criterion for drug-induced hypersensitivity pneumonitis [13, 47], must be interpreted according to the circumstances, which varied across patients. In 13 patients, the data were highly compatible with drug causation. In the 32 remaining patients, the data remained compatible with drug causation. Five among these 32 patients gave negative rechallenge results but either received steroids at an unspecified dosage $(n=3)$

\section{TABLE 5 Modified criteria for assessing drug causation o lung disease}

\footnotetext{
Intrinsic criteria from the clinical analysis

Timing

Clinical manifestations

Exclusion

Specific site of treated disease

Infection

Other condition or exacerbation of a previous condition (e.g. heart failure and pulmonary embolism)

Favourable outcome following discontinuation of the suspected drug

Positive results following accidental or intentional rechallenge

Extrinsic criteria from the literature

Same as the intrinsic criteria when the pattern of lung disease has been reported previously with the same drug

Rate of occurrence, interpreted according to the time the drug has been on the market

Confrontation of intrinsic and extrinsic criteria

Similarity of the clinical presentation, time to onset and course

Data from [13]
} 
$[30,39]$ or had ARDS, i.e. a manifestation probably unrelated to hypersensitivity [19].

\section{Pathogenic mechanisms and precautions for use}

The three clinical presentations of rituximab-induced lung disease may differ regarding their underlying mechanism. Early-onset ARDS is probably unrelated to hypersensitivity. Indeed, immediate hypersensitivity would be expected to produce symptoms within a few minutes after the beginning of the infusion, in most cases after at least one previous cycle. Instead, ARDS symptoms started after a few hours, suggesting an IRR related to cytokine release and/or tumour lysis syndrome [10]. This mechanism is consistent with the occurrence of early-onset ARDS in patients receiving multiple cytotoxic agents and at the first cycle, i.e. when the tumour burden is greatest, or with circulating malignant B-cells. Similarly, early-onset ARDS is exceedingly rare in patients treated with rituximab alone for systemic diseases. Additionally supporting this mechanism is the negative response to rechallenge in two patients and the inconsistent efficacy of premedication, only $10 \%$ in clinical trials [4]. Therefore, close monitoring is in order at the first cycle, particularly in patients receiving combination chemotherapy for high-burden lymphoma. Recommendations concerning serious side-effects should be followed (table 1) [10]. Higher-dose steroid therapy may deserve consideration.

Acute or subacute rituximab-induced lung disease, most notably organising pneumonia, probably reflects a hypersensitivity reaction to the potentially immunogenic chimeric antiCD20 antibody. Arguments that support a hypersensitivity reaction include the recurrence and increasing severity of the symptoms from one infusion to the next, occurrence during the third month on average, responsiveness to steroid therapy (delayed onset 15 days after the methylprednisolone infusion and favourable outcome with steroid therapy), rash and eosinophilia, BALF lymphocytosis and histological pattern of organising pneumonia in many patients [48]. The potential for severity lies in the risk of a delayed diagnosis, with the initial reversible symptoms being overlooked as a result of inadequate knowledge of this complication.

Given the potential severity of rituximab-induced lung disease and the strong suspicion of underlying hypersensitivity, we suggest a number of recommendations (table 1). First, patients should be told that respiratory disease may develop, with the risk being greatest $\sim 15$ days after the last infusion and around the fourth cycle. Secondly, respiratory symptoms should be routinely sought after each infusion. Thirdly, any clinical manifestation, however mild, should prompt chest radiography. Finally, when the findings support a diagnosis of rituximab-induced lung disease, steroid therapy should be started immediately, as it seems to improve the outcome. Furthermore, instead of the currently recommended methylprednisolone infusion at each rituximab administration, a longer period of steroid therapy, with tapering of the dose to avoid a rebound reaction, may be appropriate.

Late-onset organising pneumonia (which may occur up to several months after the last rituximab infusion) may be related either to toxicity of the drug, whose biological half-life is poorly known but probably long, or to immune system restoration [49]. Although not severe, these forms require histological confirmation as the nodules may suggest a malignancy or a chronic infection in these immunocompromised patients.

\section{Conclusion}

In conclusion, the present study confirms the pulmonary toxicity of rituximab. Our data should prove helpful to clinicians in assessing causality in patients with respiratory symptoms following rituximab therapy. Three distinct clinical presentations were identified according to time to onset, suggesting different underlying mechanisms. For each, we suggest specific recommendations. Pulmonologists must ensure the early diagnosis and treatment of rituximab-induced lung disease and inform other specialists of this complication and of the need for close monitoring of respiratory status.

\section{SUPPORT STATEMENT}

Translation of the present study was supported by the Study and Research Group in Pneumology (Pneumology Service, Tenon Hospital, Paris, France).

\section{STATEMENT OF INTEREST}

A statement of interest for F. Lioté can be found at www.erj. ersjournals.com $/ \mathrm{misc} /$ statements.dtl

\section{ACKNOWLEDGEMENTS}

We thank the nonprofit organisation Study and Research Group in Pneumology (Pneumology Service, Tenon Hospital, Paris, France) for funding the translation of this article.

\section{REFERENCES}

1 Friedberg JW. Unique toxicities and resistance mechanisms associated with monoclonal antibody therapy. Hematology Am Soc Hematol Educ Program, 2005: 329-334.

2 Kimby E. Tolerability and safety of rituximab (MabThera $\left.{ }^{\circledR}\right)$. Cancer Treat Rev 2005; 31: 456-473.

3 Byrd JC, Peterson BL, Morrison VA, et al. Randomized phase 2 study of fludarabine with concurrent versus sequential treatment with rituximab in symptomatic, untreated patients with B-cell chronic lymphocytic leukemia: results from cancer and leukemia group B 9712 (CALGB 9712). Blood 2003; 101: 6-14.

4 Sibilia J, Gottenberg JE, Mariette X. Rituximab: a new therapeutic alternative in rheumatoid arthritis. Joint Bone Spine 2008; 75: 526-532.

5 Arnold DM, Dentali F, Crowther MA, et al. Systematic review: efficacy and safety of rituximab for adults with idiopathic thrombocytopenic purpura. Ann Intern Med 2007; 146: 25-33.

6 Solal-Celigny P. Safety of rituximab maintenance therapy in follicular lymphomas. Leuk Res 2006; 30: S16-S21.

7 Cvetković RS, Perry CM. Rituximab: a review of its use in nonHodgkin's lymphoma and chronic lymphocytic leukaemia. Drugs 2006; 66: 791-820.

8 Mohrbacher A. B cell non-Hodgkin's lymphoma: rituximab safety experience. Arthritis Res Ther 2005; 7: S19-S25.

9 González V, Salgueiro E, Jimeno FJ, et al. Post-marketing safety of antineoplasic monoclonal antibodies: rituximab and trastuzumab. Pharmacoepidemiol Drug Saf 2008; 17: 714-21.

10 Smolen JS, Keystone EC, Emery P, et al. Consensus statement on the use of rituximab in patients with rheumatoid arthritis. Ann Rheum Dis 2007; 66: 143-150.

11 Looney RJ, Srinivasan R, Calabrese LH. The effects of rituximab on immunocompetency in patients with autoimmune disease. Arthritis Rheum 2008; 58: 5-14. 
12 Bégaud B, Evreux JC, Jouglard J, et al. Imputabilité des effets inattendus ou toxiques des médicaments. Actualisation de la méthode utilisée en France. [Imputation of the unexpected or toxic effects of drugs. Actualization of the method used in France.] Thérapie 1985; 40: 111-118.

13 Mayaud C, Fartoukh M, Parrot A, et al. Les pneumopathies infiltrantes diffuses d'origine médicamenteuse: un problème avant tout diagnostique. [Drug-associated interstitial lung disease: a diagnostic challenge.] Rev Pneumol Clin 2005; 61: 179-185.

14 Davis TA, White CA, Grillo-López AJ, et al. Single-agent monoclonal antibody efficacy in bulky non-Hodgkin's lymphoma: results of a phase II trial of rituximab. J Clin Oncol 1999; 17: 18511857.

15 Hainsworth JD, Litchy S, Lamb MR, et al. First line treatment with brief-duration chemotherapy plus rituximab in elderly patients with intermediate-grade non-Hodgkin's lymphoma: phase II trial. Clin Lymphoma 2003; 4: 36-42.

16 Soubrier M, Jeannin G, Kemeny JL, et al. Organizing pneumonia after rituximab therapy: two cases. Joint Bone Spine 2008; 75: 362-365.

17 Saito B, Nakamaki T, Adachi D, et al. Acute respiratory distress syndrome during the third infusion of rituximab in a patient with follicular lymphoma. Int J Hematol 2004; 80: 164-167.

18 Montero AJ, McCarthy JJ, Chen G, et al. Acute respiratory distress syndrome after rituximab infusion. Int J Hematol 2005; 82: 324-326.

$19 \mathrm{Wu}$ SJ, Chou WC, Ko BS, et al. Severe pulmonary complications after initial treatment with rituximab for the Asian-variant of intravascular lymphoma. Haematologica 2007; 92: 141-142.

20 Kanelli S, Ansell SM, Habermann TM, et al. Rituximab toxicity in patients with peripheral blood malignant B-cell lymphocytosis. Leuk Lymphoma 2001; 42: 1329-1337.

21 Burton C, Kaczmarski R, JanMohamed R. Interstitial pneumonitis related to rituximab therapy. N Engl J Med 2003; 348: 2690-2691.

22 Jullien V, Perrin C, Peyrade F, et al. Alveolar hypoxemic interstitial pneumonia related to rituximab therapy. Rev Mal Respir 2004; 2: 407-410.

23 Feenstra JF, Hickey BP, Blackwell EA. Acute respiratory failure associated with cladribine pneumonitis (rituximab induced?) Intern Med J 2004; 34: 583-584.

24 Leon RJ, Gonsalvo A, Salas R, et al. Rituximab-induced acute pulmonary fibrosis. Mayo Clin Proc 2004; 79: 949-953.

25 Alexandrescu DT, Dutcher JP, O'Boyle K, et al. Fatal intra-alveolar hemorrhage after rituximab in a patient with non-Hodgkin lymphoma. Leuk Lymphoma 2004; 45: 2321-2325.

26 Swords R, Power D, Fay M, et al. Interstitial pneumonitis following rituximab therapy for immune thrombocytopenic purpura (ITP). Am J Hematol 2004; 77: 103-104.

27 Macartney C, Burke E, Elborn S, et al. Bronchiolitis obliterans organizing pneumonia in a patient with non-Hodgkin's lymphoma following R-CHOP and pegylated filgrastim. Leuk Lymphoma 2005; 46: 1523-1526.

28 Hiraga J, Kondoh Y, Taniguchi $\mathrm{H}$, et al. A case of interstitial pneumonia induced by rituximab therapy. Int J Hematol 2005; 81: 169-170.

29 Ghesquieres H. Severe interstitial pneumonitis following rituximab and bleomycin-containing combination chemotherapy. Ann Oncol 2005; 16: 1399.

30 Motl SE, Baskin RC. Delayed-onset grade 4 neutropenia associated with rituximab therapy in a patient with lymphoma: case report and literature review. Pharmacotherapy 2005; 25: 1151-1155.

31 Herishanu Y, Polliack A, Leider-Trejo L, et al. Fatal interstitial pneumonitis related to rituximab-containing regimen. Clin Lymphoma Myeloma 2006; 6: 407-409.
32 Mian M, Rass C, Hutarew G, et al. Extensive organizing pneumonia during chemo-immunotherapy containing rituximab and G-CSF in a patient with diffuse large B-cell lymphoma: case report and review of the literature. Leuk Lymphoma 2006; 47: 16831685.

33 Biehn SE, Kirk D, Rivera MP, et al. Bronchiolitis obliterans with organizing pneumonia after rituximab therapy for non-Hodgkin's lymphoma. Hematol Oncol 2006; 24: 234-237.

34 Lee Y, Kyung SY, Choi SJ, et al. Two cases of interstitial pneumonitis caused by rituximab therapy. Korean J Intern Med 2006; 21: 183-186.

35 Wagner SA, Mehta AC, Laber DA. Rituximab-induced interstitial lung disease. Am J Hematol 2007; 82: 916-919.

36 Kim KM, Kim HC, Jeon KN, et al. Rituximab-CHOP induced interstitial pneumonitis in patients with disseminated extranodal marginal zone B cell lymphoma. Yonsei Med J 2008; 49: 155.

37 Tonelli AR, Lottenberg R, Allan RW, et al. Rituximab-induced hypersensitivity pneumonitis. Respiration 2009; 78: 225-229.

38 Nieuwenhuizen L, Verzijlbergen FJ, Wiltink E, et al. A possible role of ${ }^{18} \mathrm{~F}-\mathrm{FDG}$ positron-emission tomography scanning in the early detection of rituximab-induced pneumonitis in patients with nonHodgkin's lymphoma. Haematologica 2008; 93: 1267-1269.

39 Liu X, Hong XN, Gu YJ, et al. Interstitial pneumonitis during rituximab-containing chemotherapy for non-Hodgkin lymphoma. Leuk Lymphoma 2008; 49: 1778-1783.

40 Heresi GA, Farver CF, Stoller JK. Interstitial pneumonitis and alveolar hemorrhage complicating use of rituximab: case report and review of the literature. Respiration 2008; 76: 449-453.

41 Jaffre S, Jardin F, Dominique S, et al. Fatal haemoptysis in a case of lymphomatoid granulomatosis treated with rituximab. Eur Respir J 2006; 27: 644-646.

42 American Thoracic Society/European Respiratory Society. International multidisciplinary consensus classification of the idiopathic interstitial pneumonias. Am J Respir Crit Care Med 2002; 165: 277304.

43 Agbabiaka TB, Savoviæ J, Ernst E. Methods for causality assessment of adverse drug reactions: a systematic review. Drug Saf 2008; 31: 21-37.

44 Lioté H, Séroussi B, Bouaud J, et al. Formalisation de la démarche diagnostique des pneumopathies médicamenteuses: le système PneumoDoc. [PneumoDoc: a computer-based decision-making system for drug-related pulmonary disease.] Rev Pneumol Clin 2007; 63: 193-201.

45 Mokhtari M, Bach PB, Tietjen PA, et al. Bronchiolitis obliterans organizing pneumonia in cancer: a case series. Respir Med 2002; 96: 280-286.

46 Foucher P, Camus P, Study Group of Iatrogenic Pulmonary Pathology, Pneumotox. The drug-induced lung diseases. www. pneumotox.com Date last updated: January 12, 2009. Date last accessed: January 12, 2009.

47 Benichou C, Danan G, Flahault A. Causality assessment of adverse reactions to drugs - II. An original model for validation of drug causality assessment methods: case reports with positive rechallenge. J Clin Epidemiol 1993; 46: 1331-1336.

48 Akoun GM, Mayaud CM, Touboul JL, et al. Use of bronchoalveolar lavage in the evaluation of methotrexate lung disease. Thorax 1987; 42: 652-655.

49 Naccache JM, Antoine M, Wislez M, et al. Sarcoid-like pulmonary disorder in human immunodeficiency virus-infected patients receiving antiretroviral therapy. Am J Respir Crit Care Med 1999; 159: 2009-2013. 